\title{
Scale-dependency of surface fluxes in an atmospheric mesoscale model: effect of spatial heterogeneity in atmospheric conditions
}

\author{
Jinkyu Hong and Joon Kim \\ Global Environment Lab, Department of Atmospheric Sciences, Yonsei University, Seoul 134-032, Korea
}

Received: 13 February 2008 - Revised: 15 October 2008 - Accepted: 19 October 2008 - Published: 9 December 2008

\begin{abstract}
We examined the nonlinear effect of spatial heterogeneity in atmospheric conditions on the simulation of surface fluxes in the mesoscale model, MM5 by testing their scale-invariance from a tower footprint to regional scales. The test domain was a homogeneous shortgrass prairie in the central part of the Tibetan Plateau with an eddy-covariance flux tower at the center. We found that the spatial variability resulting from changing distribution of clouds and precipitation in the model domain affected radiative forcing at the ground surface, thereby altering the partitioning of surface fluxes. Consequently, due to increasing spatial variability in atmospheric conditions, the results of MM5 did not produce convergent estimates of surface fluxes with increasing grid sizes. Our finding demonstrates that an atmospheric model can underestimate surface fluxes in regional scale not necessarily due to intrinsic model inaccuracy (e.g., inaccurate parameterization) but due to scale-dependent nonlinear effect of spatial variability in atmospheric conditions.
\end{abstract}

\section{Introduction}

Surface fluxes from the earth surface are playing a key role in climate changes by modifying the circulation of the overlying atmosphere (e.g., Avissar et al., 1989; Baldocchi et al., 2001). Regional networks of direct surface flux measurements have helped significantly to improve our understanding of soil-vegetation-atmosphere (SVAT) interactions (e.g., Baldocchi et al., 2001). In particular, they have provided a pivotal information in develping and evaluating SVAT models at plot scale $\left(\leq 1 \mathrm{~km}^{2}\right)$. So far, continuous estimation of surface fluxes is not robust beyond plot scale $\left(1-10 \mathrm{~km}^{2}\right)$ and our understanding of the SVAT interactions remains a major

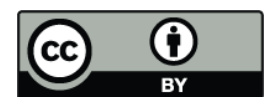

Correspondence to: Jinkyu Hong (jkhong@yonsei.kr) challenge in the regional scale (Dolman et al., 2006). Atmospheric mesoscale models have been a powerful tool and have a potential to monitor energy and mass exchanges in regional scale although modeling results are yet to be validated (e.g., Henderson-Sellers et al., 1993; Oncley and Dudhia, 1995; Chen and Dudhia, 2001a; Kerschgens and Heinemann, 2005; van der Molen and Dolman, 2007).

When we interpret the simulated SVAT processes in regional scale, it is requisite to scale down the model results because of the lack of the observation data to cover regional scale. Also, we should note that most of atmospheric numerical models implicitly assume spatial homogeneity of surface properties as well as atmospheric conditions such that they calculate gridbox averaged surface fluxes using mean variables of surface properties and meteorological fields. Indeed, spatial heterogeneity in surface properties (e.g., vegetation types) (Sellers et al., 1995; Middelburg et al., 1999; Baldocchi et al., 2005; Li et al., 2008) and in atmospheric conditions (e.g., radiative fluxes) has been a critical issue in validating numerical models and remote sensing (Bertoldi et al., 2008).

With respect to this impact of spatial heterogeneity on the model evaluation, two aspects of scaling issue are worth noting. One is related to a small size of tower footprint compared to a typical grid size of a mesoscale model. Such a difference can induce inadvertent model bias despite proper subgrid parameterizations in the model (Oncley and Dudhia, 1995; Kim et al., 2006). Previous studies, however, validated the models with grid sizes from 10 to $200 \mathrm{~km}$ against the insitu tower data of $\sim 1 \mathrm{~km}$ footprint without clear assessment of surface heterogeneity around a measurement location and in the model domain (e.g., Chen and Dudhia, 2001a; Brotzge, 2004; Pyles et al., 2003).

The other issue is the nonlinear effect due to spatial variability in surface properties and/or atmospheric conditions expressed by Jensen's inequality in mathematics (Fig. 1) (Sellers et al., 1992, 1995). Following the pioneering work of Sellers et al. (1992), many models now consider at

Published by Copernicus Publications on behalf of the European Geosciences Union and the American Geophysical Union. 


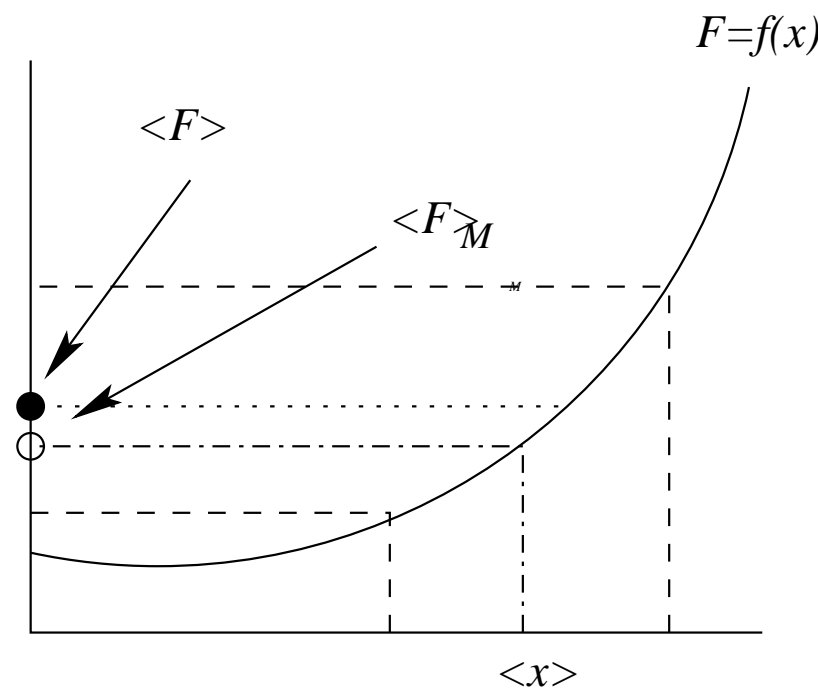

Fig. 1. Jensen's inequality. $F$ is a function of $x$ and $<>$ is an averaging operator.

least surface heterogeneity by combining different vegetation types within a grid (e.g., Bonan et al., 2002). However, compared to popular interests in the impact of spatial heterogeneity of surface properties (e.g., vegetation type) on the simulated surface fluxes, that of atmospheric conditions received little attention. Similar to the effect of surface heterogeneity on the simulated surface fluxes, spatial variability in meteorological fields for driving SVAT modules in a fully coupled mesoscale model can also result in potential bias of the modeled surface fluxes with different model grid size.

To properly assess surface fluxes at regional scales using a fully coupled atmospheric model, we attempted to quantify nonlinear effect due to the spatial variability in atmospheric conditions. Without consideration of this scaling issue, examination of the model performance on surface fluxes could lead us to a hasty conclusion that a model output agrees well with field observation or that the model has systematic bias in subgrid parameterization.

As far as we know, "scale-invariance" of surface fluxes in relation to spatial variability in atmospheric conditions has not been tested in fully coupled mesoscale models. Here, the scale-invariance of surface fluxes implies that surface fluxes aggregated from a fine grid should be equal to those from a coarse grid (Fig. 2). Therefore, such a test offers the information to constrain the simulated surface fluxes. Based on the assessment of the scale-dependency, we have evaluated the SVAT processes in the model at a tower footprint scale using in-situ tower data.

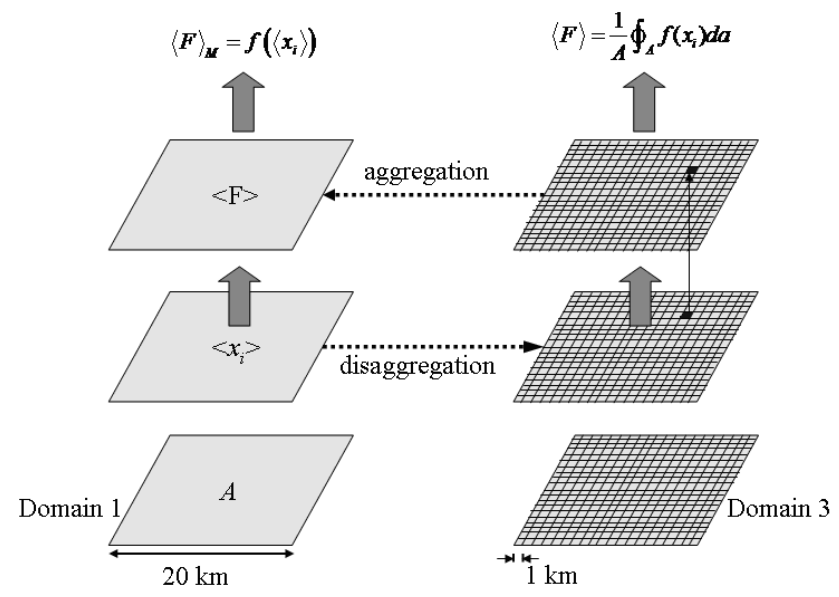

Fig. 2. The concept of (dis)aggregation and scale-invariance of surface fluxes in the model adapted from Sellers et al. (1992).

\section{Materials and methods}

2.1 Theoretical background: scale-invariance of surface fluxes

The concept of scale-invariance of surface fluxes was first proposed by Sellers et al. (1992). The test of scale-invariance can give information to constrain surface fluxes in the model. The issue of scale-invariance with respect to model performance is the extent to which the calculated surface energy balance (SEB) at coarse domain is influenced by the use of coarse-domain averaged surface boundary conditions (Fig. 2) (see Sellers et al. $(1992,1997)$ for more detailed information). If $F$ is surface flux as a function of $x_{i}$ (e.g. topography, surface conductance, soil moisture), we can write

$F=f\left(x_{1}, x_{2}, x_{3}, \ldots\right)$

Thus, complete values of $F$ over an entire domain are calculated from

$\langle F\rangle \equiv \frac{1}{A} \iint_{A} f\left(x_{i}\right) d a$

where $A$ is the area of domain and the brackets denote area average over $A$. However, because of practical reason, $F$ over an entire domain is calculated:

$\langle F\rangle_{M} \equiv f\left(\left\langle x_{i}\right\rangle\right)$

where $\langle F\rangle_{M}$ is an estimate of $\langle F\rangle$.

Ideally, surface fluxes aggregated from fine grid size should be consistent with values from coarser grid size. Soil and vegetation have, however, nonlinear responses to the atmosphere and consequently surface fluxes are not conserved (i.e., $\langle F\rangle \neq\langle F\rangle_{M}$ ). Consequently, testing the scaleinvariance of surface fluxes to the degree of spatial variability in atmospheric conditions can provide valuable information on the model evaluation. 


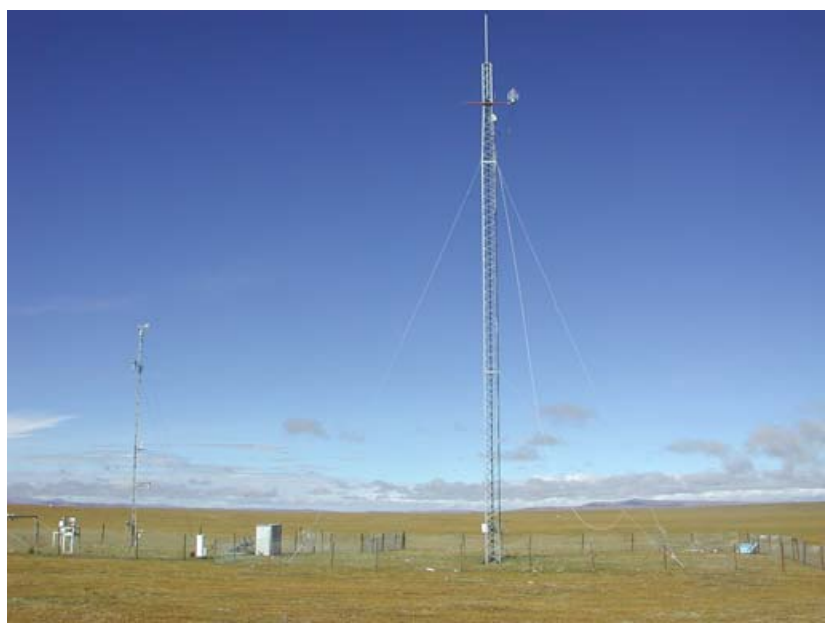

Fig. 3. Eddy-covariance system was installed at $20 \mathrm{~m}$ tower in the ANNI flux station. The site was a flat and homogeneous shortgrass prairie.

\subsection{Field observations}

We used the data collected at the ANNI flux station near Naqu, Tibet $\left(31.37^{\circ} \mathrm{N} ; 91.90^{\circ} \mathrm{E}, 4580 \mathrm{~m}\right.$ above m.s.l.) from 26 to 31 August 2002. The site was a flat and homogeneous shortgrass prairie (Fig. 3). The soil was predominantly sandy silt loam and soil surface is sparsely covered with short grass (canopy height of $<0.05 \mathrm{~m}$ and leaf area index of $<0.5$ ) due to grazing.

We used the eddy-covariance system mounted on a $20 \mathrm{~m}$ tower to measure the turbulent fluxes of sensible heat $(H)$ and latent heat $(L E)$. The system consisted of three-dimensional sonic anemometer (CSAT3, Campbell Scientific Inc., US) and infrared gas analyzer (LI7500, LiCor, US). Sampling rate was $10 \mathrm{~Hz}$ and averaging time was $30 \mathrm{~min}$. Other supporting measurements included surface radiative fluxes, soil moisture, soil temperature, and precipitation. During the study period, energy balance was nearly closed and quality assurance has been done based on Lee et al. (2004). More information on field observations at the ANNI flux station can be found in Hong et al. (2004), Hong and Kim (2008) and http://ceop.net.

\subsection{Meteorological conditions}

During the simulation period, the site was under the high pressure system centered on the eastern Tibet. The weather charts show that the position and intensity of this high pressure system had fluctuated daily and this system over the Plateau scaled down from 28 August 2002. Subsequently, the atmospheric surface pressure tended to decrease at the flux station. The atmospheric conditions at the flux station were similar to the weather chart reports and NCEP-NCAR reanalysis data (hereafter NNRD) except rainfall. Based on

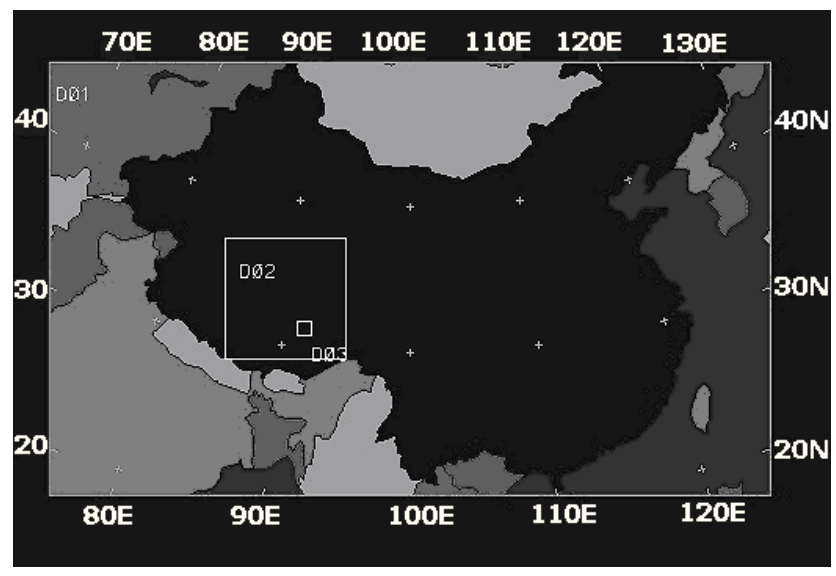

Fig. 4. The model domains. D01, D02 and D03 designate domain 1 , domain 2 , and domain 3 , respectively.

the weather charts, it was overcast on 28 and 29 August but there was no precipitation on the Plateau. However, $0.6 \mathrm{~mm}$ rainfall was recorded for an hour at the flux station in late evening of 28 August. After this rainfall, the mixing ratio increased and then slowly decreased with time and the Bowen ratio kept increasing from about 0.3 to 0.5 with decreasing soil moisture.

\subsection{Numerical experiment}

In this study, for testing scale-invariance in the atmospheric mesoscale model, we carried out the numerical simulation using Penn State/NCAR mesoscale model, MM5 from 26 to 31 August 2002. Using a nesting option, the model was run on a $60 \mathrm{~km}$ horizontal grid (domain 1) with subdomains of 20 and $1 \mathrm{~km}$ horizontal grid increments (domain 2 and domain 3, respectively) (Fig. 4). To assess the scale dependence of surface fluxes (Eq. 3), the outputs from the domain 3 were aggregated to $20 \mathrm{~km}$ grid scale. These aggregated outputs were compared with the outputs from the domain 2 simulation.

The number of vertical layers was 35 and the model top was located at $50 \mathrm{hPa}$. The initial and boundary conditions were based on NNRD. Topography data were $30 \mathrm{~s}$ tiled topography data from USGS (US Geological Survey) and monthly vegetation fraction data were from AVHRR (Advanced Very High Resolution Radiometer) (Gutman and Ignatov, 1998). For land use and soil classification, 25category USGS vegetation data and STATSGO (State Soil Geographic) 17-category soil data were utilized. The KainFritsch cumulus parameterization scheme (Kain and Fritsch, 1993) and Reisner2 microphysics scheme were used (Reisner et al., 1998) in this study. But cumulus parameterization was turned off in domain 3 because $1 \mathrm{~km}$ horizontal grid spacing in domain 3 is assumed to be small enough to resolve the cumulus convection. We used MRF PBL scheme and RRTM radiation scheme (Hong and Pan, 1996; Mlawer 


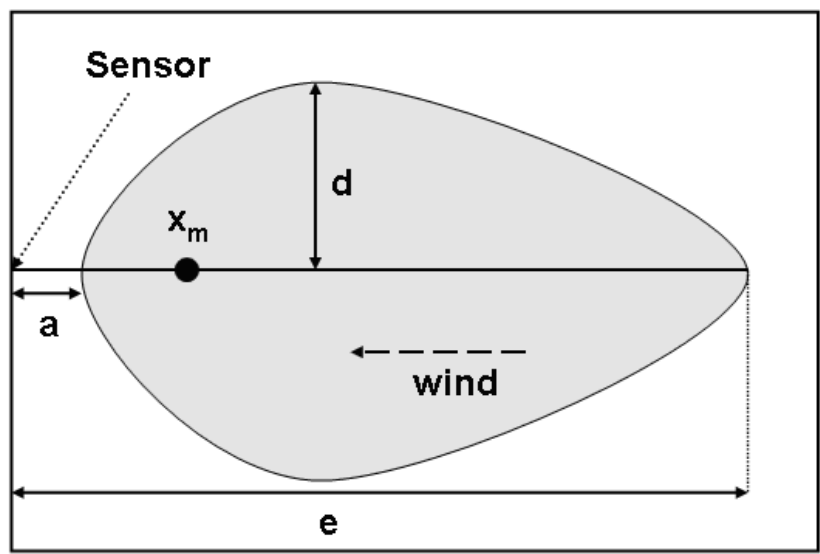

Fig. 5. Characteristic dimensions of the source area of FSAM: maximum source location $\left(x_{m}\right)$, near end $(a)$, far end $(e)$, and maximum lateral half-width $(d)$ of the source area.

et al., 1997). For land surface processes, Noah land surface model (LSM) (Koren et al., 1999) was used in this study. More information can be found on the MM5 website (http://www.mmm.ucar.edu/mm5/).

The measurement height was $20 \mathrm{~m}$ for tower observation but model outputs were from $2 \mathrm{~m}$ for temperature and humidity and $10 \mathrm{~m}$ for wind speed. For proper comparisons, the observation data were recalculated using Monin-Obukhov theory (Kaimal and Finnigan, 1994). The boundary layer processes used in this model are based on Monin-Obukhov (MO) similarity and assume that source/sink distribution is same among different scalars (i.e., temperature and water). Recently, McNaughton and Brunet (2002) suggested that surface fluxes can deviate from the prediction of MO similarity. This issue was observationally investigated by Hong et al. (2004) and Choi et al. (2004) but such a deviation does not impact on our conclusion in this study.

\subsection{Footprint analysis}

Turbulent flux and scalar concentration measurements are influenced by the underlying surface below the sensors and represent a weighted average of upwind conditions. A measured quantity, $\eta$, is given to the integrated sum of source strength distribution $\left(Q_{n}\right)$ at location $\mathrm{r}$ and footprint (or source weight distribution), $f$ (Schmid, 1997):

$\eta(\mathbf{r})=\int_{\mathfrak{R}} Q_{n}\left(\mathbf{r}+\mathbf{r}^{\prime}\right) \cdot f\left(\mathbf{r}, \mathbf{r}^{\prime}\right) \cdot d \mathbf{r}^{\prime}$

The footprint $(f)$ determines the relative weight of individual point sources. To obtain the spatial context affecting the measured quantities, the source area of level $P$ is given as:

$P=\frac{\phi_{P}}{\phi_{\mathrm{tot}}}=\frac{\iint_{\Omega_{P}} f\left(x^{\prime}, y^{\prime}, z_{m}\right) d x^{\prime} d y^{\prime}}{\int_{-\infty}^{+\infty} \int_{-\infty}^{+\infty} f\left(x^{\prime}, y^{\prime}, z_{m}\right) d x^{\prime} d y^{\prime}}$ where the source area $\left(\Omega_{P}\right)$ is the surface area bounded by a footprint isopleth $f\left(x, y, z_{m}\right)$, such that $P$ is the fraction of the total integrated footprint function $\left(\phi_{\mathrm{tot}}\right)$ and $\phi_{p}$ is the integral of the footprint over $\Omega_{P}$ (Schmid, 1997). The underlying surface area of influence of sensors continuously changes with measurement height, atmospheric stability, wind direction, and turbulence structure.

In this study, we calculated a tower footprint using fluxsource area model (FSAM) by Schmid (1997). The outputs of FSAM are the characteristic dimensions of the footprint such as maximum source location $\left(x_{m}\right)$, near end $(a)$, far end $(e)$ and maximum lateral half-width $(d)$ of the source area (Fig. 5). During the simulation period, slightly unstable conditions occurred more frequently and data were evenly distributed for the wind directions except northeasterly. During the daytime, average $e$ and $d$ were about $400 \mathrm{~m}$ and $40 \mathrm{~m}$. On the other hand, in the nighttime, average $e$ and $d$ increased up to about $7 \mathrm{~km}$ and $4 \mathrm{~km}$, respectively.

\section{Results and discussion}

\subsection{Test of scale-invariance of surface fluxes}

Figure 6 presents time series of sensible $(H)$ and latent heat fluxes $(L E)$ from the tower observation, reanalysis data and the model. $H$ and $L E$ from domain 3 (1 km grid size) reproduced the observed patterns and their magnitudes compared relatively well to those from domain 1 (20 km grid size) (Table 1). However, the overestimation of cloud and precipitation amount in the model caused the poor model performance, and yet the inappropriately simulated pattern in domain 1 produced a relatively good performance in rainy days. Here, we note that the surface fluxes at domain 1 and 3 were comparable in the beginning of the simulation and then diverged with time. This emphasizes that the model outputs can have inconsistent patterns with different grid sizes compared to the observation.

This discrepancy of the outputs from different grids was proportional to the domain averaged standard deviation of surface fluxes in the model (Table 2). The domain averaged standard deviation increased as the numerical integration progressed, indicating the enhanced spatial variability with time. Two-dimensional Fourier transform also corroborates that the spatial variabilities of surface fluxes increased in the model as the numerical integration progressed (Fig. 8). We speculate that this is the result of homogeneous initial and boundary conditions disaggregated down from the coarse domain. In the early period of the simulation, initial and boundary conditions for domain 3 were obtained from domain 2 by linear interpolation and thus had relatively homogenous field. As the numerical integration progressed, the model eventually made its own heterogeneity of meteorological fields and surface fluxes. It also suggests that a spin-up process is 


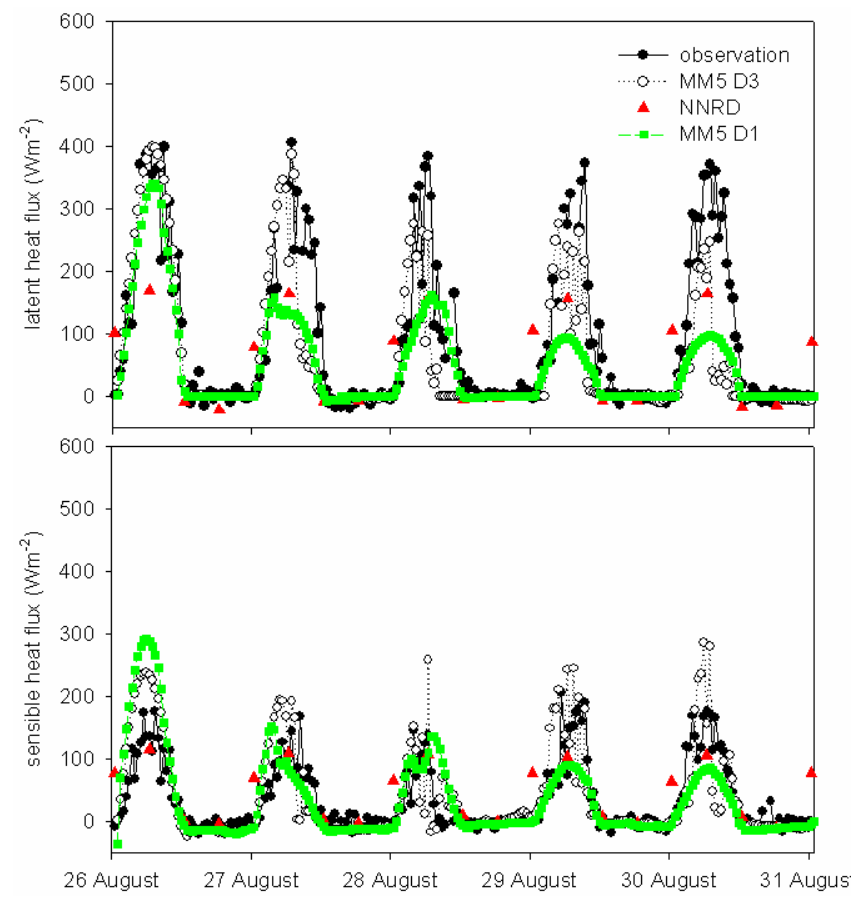

Fig. 6. Comparison of diurnal variation of sensible $(H)$ and latent heat fluxes $(L E)$. D1 and D3 are outputs from domain $1(60 \mathrm{~km}$ resolution) and domain 3 (1 km resolution), respectively. NNRD is the outputs from NCEP-NCAR reanalysis data $\left(2.5^{\circ} \times 2.5^{\circ}\right)$ near the tower.

required at least for one day so that the model adapts itself from the smooth boundary conditions.

Our analysis shows that this increased spatial variability of $H$ and $L E$ is directly related to spatial distribution of clouds and precipitation in the model. The amount of cloud and precipitation directly affects the downward radiation at the surface, which in turn limits the available energy for other surface fluxes such as $H$ and $L E$ (Fig. 7). Until now it was not certain that such an increased heterogeneity reflects the real environment because we only had the data to cover about $1 \mathrm{~km}$ domain. However, the domain 3 outputs well captured the observed patterns and magnitudes of surface fluxes and this increased heterogeneity eventually resulted in the failure of the scale-invariance of surface fluxes in the larger domain (Table 3).

A plausible explanation of this failure can be explained by the surface radiatve forcing due to the spatial variability in clouds and rainfall in the model. Surface fluxes respond to radiative forcing as the cosine function (Sellers et al., 1997). In case of spatial variability of radiative forcing caused by moderate terrain, Sellers et al. (1997) showed that this nonlinear effect can be negligible. However, in our study, surface radiation spatially spread over wide ranges because of the enhanced spatial variability in clouds and precipitation, and consequently the nonlinearity was not negligible. Under
Table 1. Index of agreement $d$ of the simulated surface fluxes $\left(\equiv 1-\left[\sum\left(M_{i}-O_{i}\right)^{2} / \sum\left(\left|M_{i}\right|+\left|O_{i}\right|\right)^{2}\right], 0 \leq d \leq 1\right)$. Here $M_{i}$ and $O_{i}$ are the simulated and observed values respectively. $d$ is 1 for a perfect model (Willmott, 1982).

\begin{tabular}{cccc}
\hline & & clear days & rainy days \\
\hline domain3 & $L E$ & 0.92 & 0.53 \\
& $H$ & 0.89 & 0.66 \\
\hline \multirow{2}{*}{ domain1 } & $L E$ & 0.86 & 0.85 \\
& $H$ & 0.88 & 0.49 \\
\hline
\end{tabular}

Table 2. Standard deviation of $L E\left(\sigma_{L E}\right)$ and $H\left(\sigma_{H}\right)$ from the domain 3 averaged mean values at 05:00 UTC.

\begin{tabular}{lcc}
\hline & $\sigma_{L E}\left(\mathrm{Wm}^{-2}\right)$ & $\sigma_{H}\left(\mathrm{Wm}^{-2}\right)$ \\
\hline 26 August & 42 & 31 \\
27 August & 67 & 73 \\
28 August & 52 & 95 \\
29 August & 43 & 108 \\
30 August & 55 & 117 \\
\hline
\end{tabular}

this condition, we can no longer approximate the response of SEB to such varying radiation with a linear function and thus the scale-invariance is not satisfied. Also, unlike Sellers et al. (1997), spatial variability of soil water contents did not decrease as the study area dried out because of the local scale precipitation in the domain and the patchiness of $L E$ (Fig. 7). Under these conditions, the model does not provide convergent estimate of surface fluxes in coarse grid simulation.

\subsection{Model validation using a tower observation}

Overall, the domain 3 simulation credibly reproduced the magnitudes and patterns of surface fluxes on clear days (Table 1). The model, however, did not properly simulate precipitation and clouds even in domain 3 (Table 1; Fig. 9). On 28 August, there were afternoon rainfalls in both the observation and the model and the model captured well the immediate reduction of the downward shortwave radiation due to this rainfall. However, the total amount of precipitation on 28 August was different from the observed precipitation. Furthermore, the duration of the rainfall in the model was longer $(\sim 5 \mathrm{~h})$ than that of the observation $(\sim 1 \mathrm{~h})$ and larger amount of clouds continued for longer period in the model. On 27, 29, and 30 August, there were small amount of rainfalls in the model $(<2.5 \mathrm{~mm} / 30 \mathrm{~min})$ but these rainfalls were not observed at the flux station. Such bias of precipitation in the model substantially reduced the downward radiative fluxes and other surface fluxes through the reduction of available energy (Table 1; Fig. 6). 
Table 3. Comparison of $L E, H$, downward shortwave radiation $\left(R_{\mathrm{sdn}}\right)$ and soil water content in domain $2(20 \mathrm{~km}$ grid size $)$ and in domain 1 after aggregating to $20 \mathrm{~km}$ spatial scale around a flux tower at 05:00 UTC. Value in a parenthesis is a standard error from the spatial average. D2, D3, and Obs are the data from domain2, domain3, and observation, respectively.

\begin{tabular}{|c|c|c|c|c|c|c|c|}
\hline & \multicolumn{4}{|c|}{$H\left(\mathrm{Wm}^{-2}\right)$} & \multicolumn{3}{|c|}{$L E\left(\mathrm{Wm}^{-2}\right)$} \\
\hline & $\mathrm{D}$ & & D3 & Obs & D2 & D3 & Obs \\
\hline 26 August & 285 & $( \pm 5)$ & $282( \pm 11)$ & 174 & $311( \pm 5)$ & $312( \pm 12)$ & 488 \\
\hline \multirow[t]{3}{*}{30 August } & 60 & $( \pm 5)$ & $158( \pm 11)$ & 177 & $105( \pm 5)$ & $156( \pm 12)$ & 354 \\
\hline & \multicolumn{4}{|c|}{$R_{\mathrm{sdn}}\left(\mathrm{Wm}^{-2}\right)$} & \multicolumn{3}{|c|}{ soil water content $\left(\mathrm{m}^{3} \mathrm{~m}^{-3}\right)$} \\
\hline & \multicolumn{2}{|c|}{ D2 } & D3 & Obs & D2 & D3 & Obs \\
\hline 26 August & 1071 & $( \pm 2)$ & $1042( \pm 3)$ & 1049 & $0.326( \pm 0.000)$ & $0.322( \pm 0.003)$ & 0.398 \\
\hline 30 August & 347 & $( \pm 2)$ & $424( \pm 94)$ & 1126 & $0.318( \pm 0.002)$ & $0.308( \pm 0.004)$ & 0.302 \\
\hline
\end{tabular}

The rainfall in domain $3(1 \mathrm{~km}$ resolution) around the tower was the grid resolvable rainfall, but not the grid resolvable rainfall in domain 2 (20 km resolution). It indicates that the convective system was of the order of a few kilometers in the model. On the other hand both convective and non-convective rainfall existed together in domain $1(60 \mathrm{~km}$ resolution), suggesting that precipitation had different origin and features with different grid sizes.

While previous studies have reported the overestimation of downward shortwave radiation in mesoscale models, which was attributed to the lack of aerosol parameterization in the radiation schemes (e.g., Betts et al., 1997; Chen and Dudhia, 2001b), the simulated downward shortwave radiation was consistently larger except around noon on clear days. Our result indicates that the optical depth in the model was shallower at high solar zenith angle but thicker at low solar zenith angle over the high elevation area like the study site (Fig. 9). Indeed, Reiter et al. (1987) reported that the atmosphere over the study site was highly transmissive and there was an additional scattering source from cumulus clouds, thus overestimating the diffusive radiation at high solar zenith angle.

Similarly, the model also overestimated the downward longwave radiation, indicating that the modeled atmosphere was warmer than the observation. In particular, such an overestimation was more pronounced when there was rainfall. Chen and Dudhia (2001b) also reported a similar overestimation of downward longwave radiation in the MM5 mesoscale model. In the radiative transfer scheme used in this study, the downward longwave radiation depends on the amount of water vapor in the atmospheric column through the modification of emissivity. Therefore, we speculate that such bias of downward longwave radiation was the result of the overestimated clouds and water vapor in the model.

The simulated wind speeds were smaller than the observation in general (not shown here). On the contrary the model overestimated friction velocity $\left(u_{*}\right)$ except for the underestimation in the nighttime conditions due to the minimum $u_{*}$ assigned in Noah LSM. This manifests that roughness length in the model was relatively large, thereby reducing wind speed excessively. Also, this suggests that the minimum friction velocity in the Noah LSM should be modified. Interestingly, the relative deviation of the simulated $u_{*}$ from the observed $u_{*}$ showed the scale-dependence on the tower footprint (Fig. 10). Tower footprints were $>1 \mathrm{~km}$ in nighttime and probably include more heterogeneous surface than well mixed daytime turbulence conditions. Accordingly, such dependence might be related to the scaling issue due to surface heterogeneity or the model's systematic bias between day and night. To accurately address this scaling issue, the potential bias of flux observations due to the footprint mismatch should be quantified with satellite image analysis (Kim et al., 2006).

Figure 11 shows diurnal variations of surface temperature and soil water content in the model with the observation. Similar to the simulated downward shortwave radiation, the model produced surface skin temperature $\left(T_{S}\right)$ on clear days comparable to to the observation but $T_{s}$ decreased rapidly near sunset due to the inappropriate rainfall simulation. In case of soil moisture, the model systematically underestimated soil water content. The observed soil water content decreased monotonically with time during the study period. The soil water content in the model also decreased with time but slightly increased due to the precipitation on 28 August. The initial value of soil water content in the model deviated from the observed values but this discrepancy was reduced mainly due to the excessive rainfall in the model. It is also worth noting that the model reproduced $L E$ relatively well despite the systematically smaller soil water contents than the observation. This is likely through strong atmospheric evaporative demands in the model. Indeed the simulated relative humidity was smaller than the observed value, and the reduction of soil water content for $L E$ was partially compensated with the excessive rainfall in the model. 
(a)

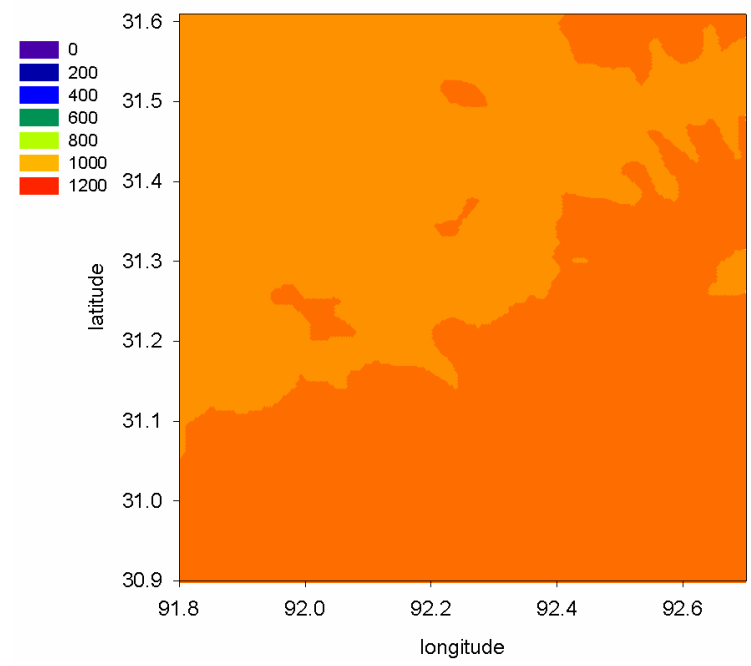

(c)

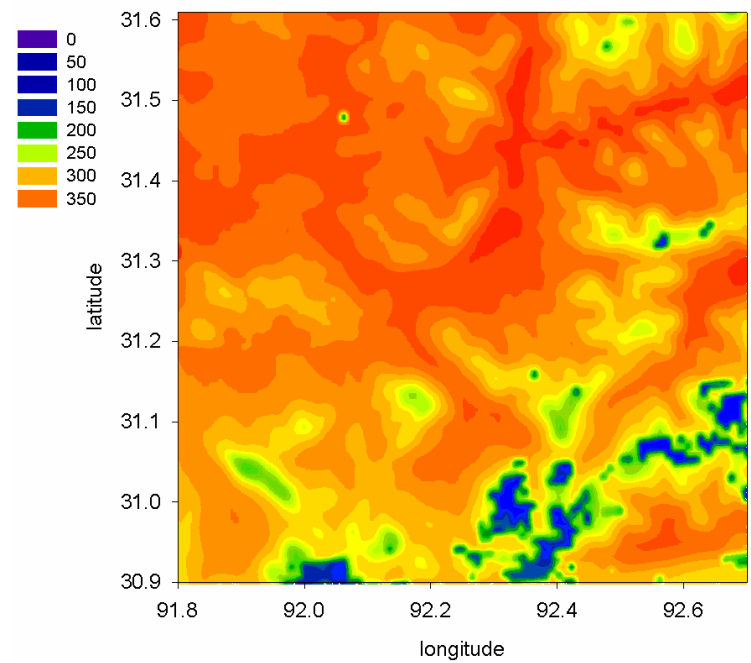

(e)

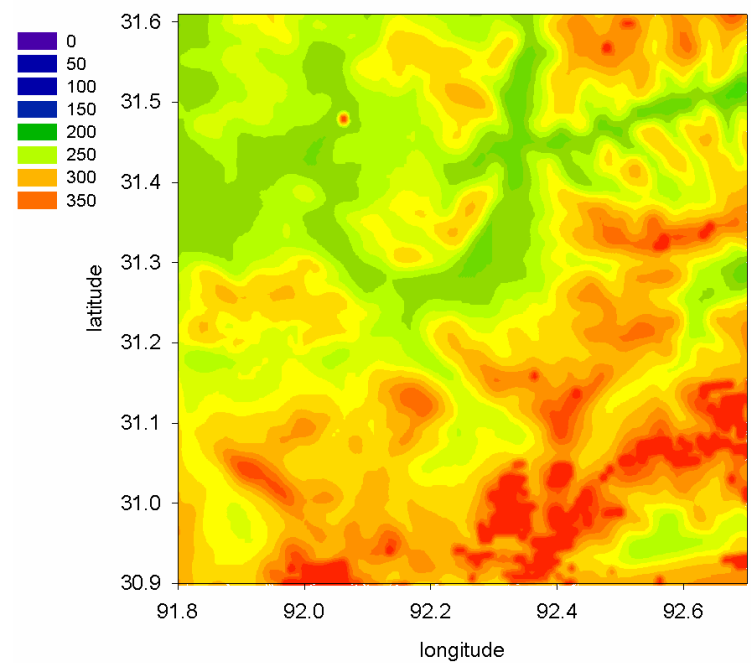

(b)

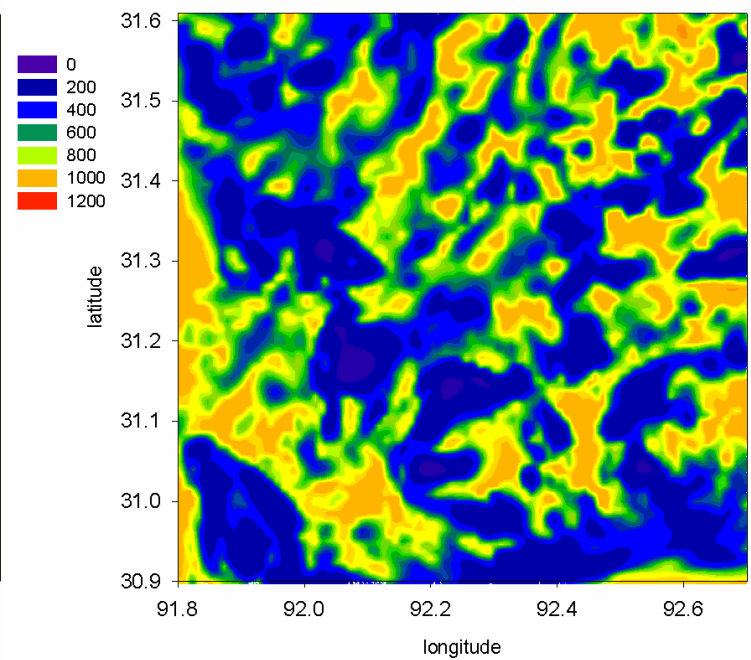

(d)

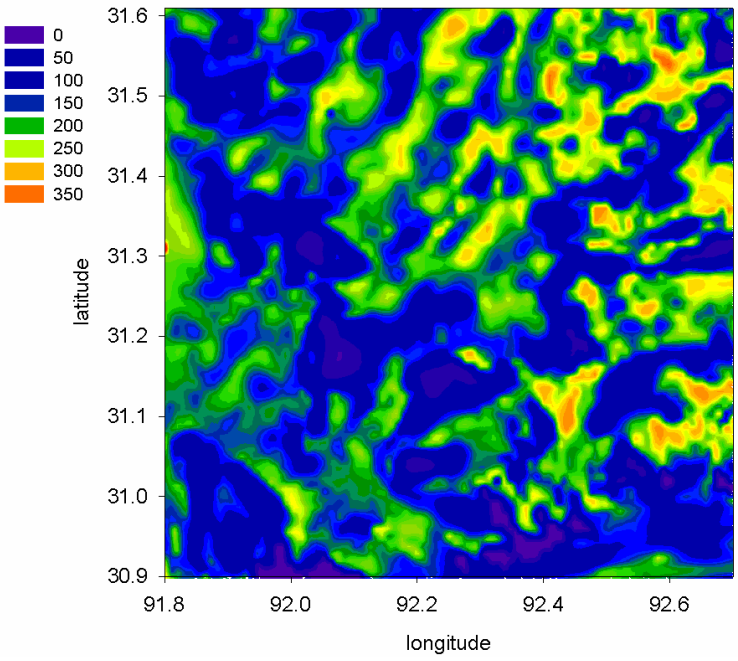

(f)

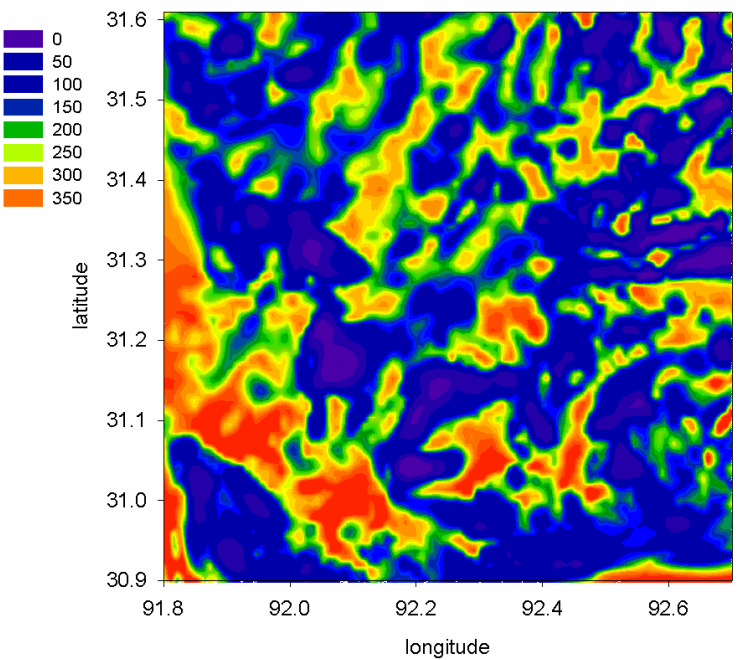

Fig. 7. Evolution of simulated surface fluxes. (a), (c) and (e) are downward shortwave radiation, $L E$ and $H$ at 05:00 UTC, 26 August, respectively: (b), (d) and (f) are downward shortwave radiation, $L E$ and $H$ at 05:00 UTC, 30 August respectively. 

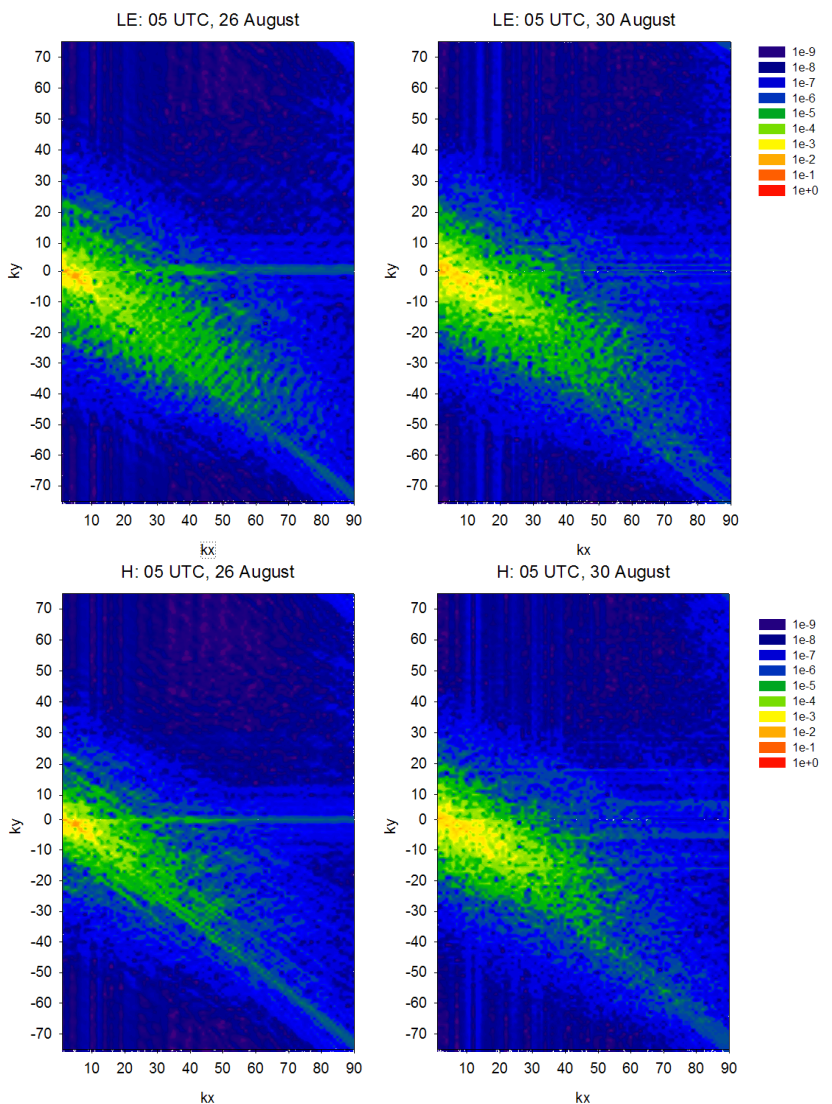

Fig. 8. Base-10 logarithm of 2-dimensional power spectrum density of $L E$ and $H$ at 05:00 UTC on 26 and 30 August. $k_{x}$ and $k_{y}$ is a wave number of longitudinal and latitudinal direction, respectively.

\section{Summary and Conclusions}

We investigated the scale-dependency of surface fluxes due to spatial variability of atmospheric conditions in the mesoscale model. To properly assess the scale-dependency with different grid sizes, we performed a numerical simulation from a tower footprint to regional scale using the atmospheric mesoscale model.

Overall, the mesoscale model well captured the diurnal variation of surface fluxes on clear days in the spatial scales of the tower footprint. However, large scale atmospheric features, which produced the conditions favorable to convective systems in the coarse domain, induced the overestimation of the amount of clouds and precipitation even in the fine resolution. Eventually the growth of those convective systems led to the increase of spatial heterogeneity in surface radiative forcing within the model domain. As the degree of spatial heterogeneity in the meteorological fields grew up in the model, surface fluxes from different grid sizes showed the scale-dependency. Accordingly, the model did not provide convergent estimates of surface fluxes to the aggregation and disaggregation processes in different grid sizes.

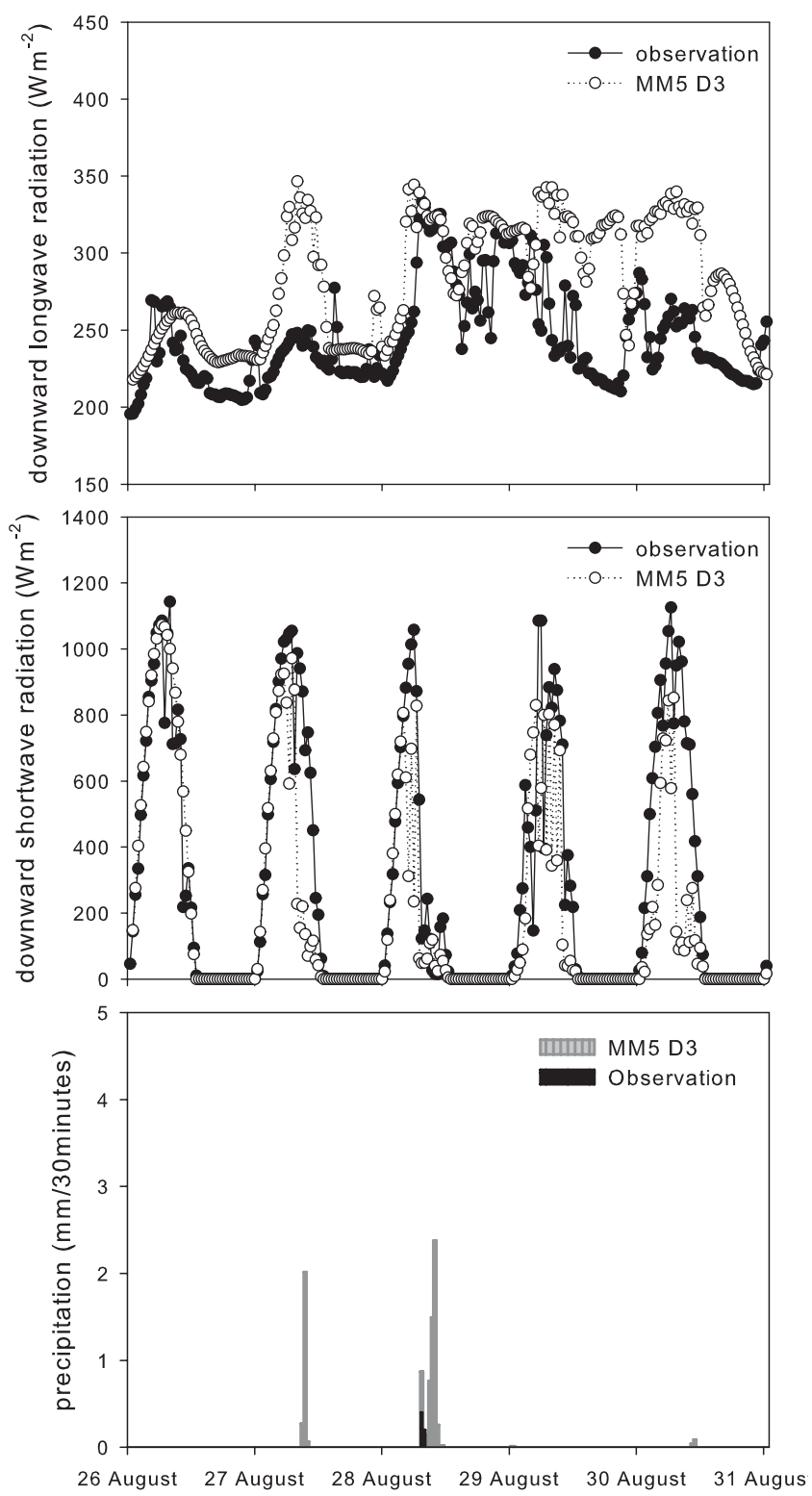

Fig. 9. Comparison of the simulated (domain 3) and observed downward longwave and shortwave radiation and precipitation.

Sellers et al. (1997) showed the insignificant impacts of surface heterogeneity on surface fluxes in the off-line biosphere model by assuming that atmospheric conditions were relatively homogeneous. In our study, however, substantial spatial variability in atmospheric conditions was generated in the fully coupled mesoscale model, which ultimately led to the failure of scale-invariance. Furthermore, our study demonstrates that the surface heterogeneity in soil moisture and temperature was imposed by larger scale constraints such as the convective rain and radiative forcing in the model. 


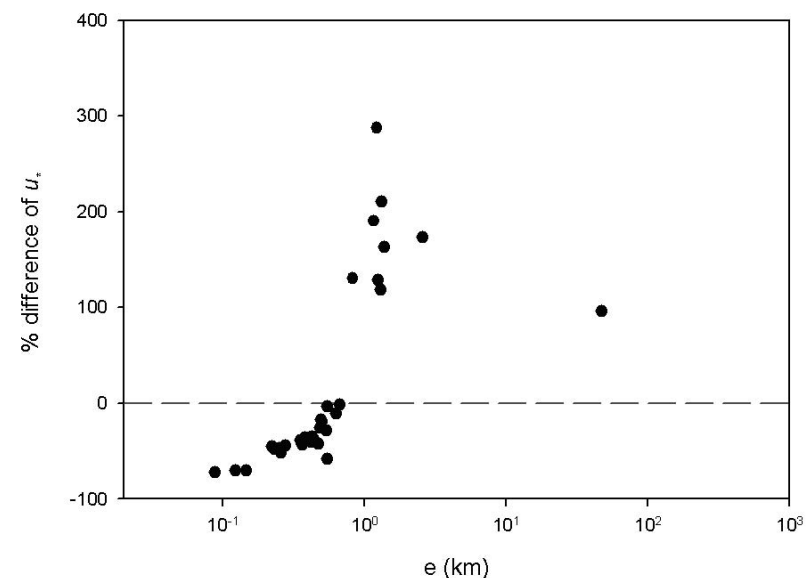

Fig. 10. Ratio of $u_{*}$ differences between the model and observation with far end distance, $e$.

Our findings have an important implication when we evaluate surface fluxes in regional and continental scales using the atmospheric model: 1) One should carefully apply the modeling outputs from a coarse domain for inferring regional scale surface fluxes because the modeled surface fluxes can be underestimated due to the failure of scale-invariance as the spatial heterogeneity grows up in the model; and 2) any difference between model outputs and the observation data can result from the failure of scale-invariance. That is, the model bias will not necessarily result from the intrinsic model inaccuracy when spatial variability in atmospheric conditions prevails. Only when the scale-invariance requirement is satisfied, one can relate the model biases to the structural deficiencies of model. In case of the scale-dependent surface fluxes, we may need to add the scale-dependent areaaveraged forms of the parameterization for a proper assessment of regional surface fluxes (Sellers et al., 1997). Otherwise, we need to aggregate surface fluxes from the fine resolution simulation of the tower footprint.

Acknowledgements. This research was supported by a grant (code: 1-8-3) from Sustainable Water Resources Research Center for 21st Century Frontier Research Program, the A3 Foresight program of the Korean Science and Engineering Foundation, and BK21 Program from the Ministry of Education and Human Resources Management of Korea. Original data are provided within the framework of GAME/ CAMP Tibet (CEOP) Scientific and Technological Research Project of Korea, Japan, and China. The first author was partially supported by the Korean Research Foundation Grant funded by the Korean Government (MOEHRD) (KRF-2006-214-C00095). Our thanks go to H. P. Schmid and S.-Y. Hong for their valuable insight. We gratefully acknowledge two anonymous reviewers for providing constructive comments on this paper.

Edited by: V. Shrira

Reviewed by: two anonymous referees

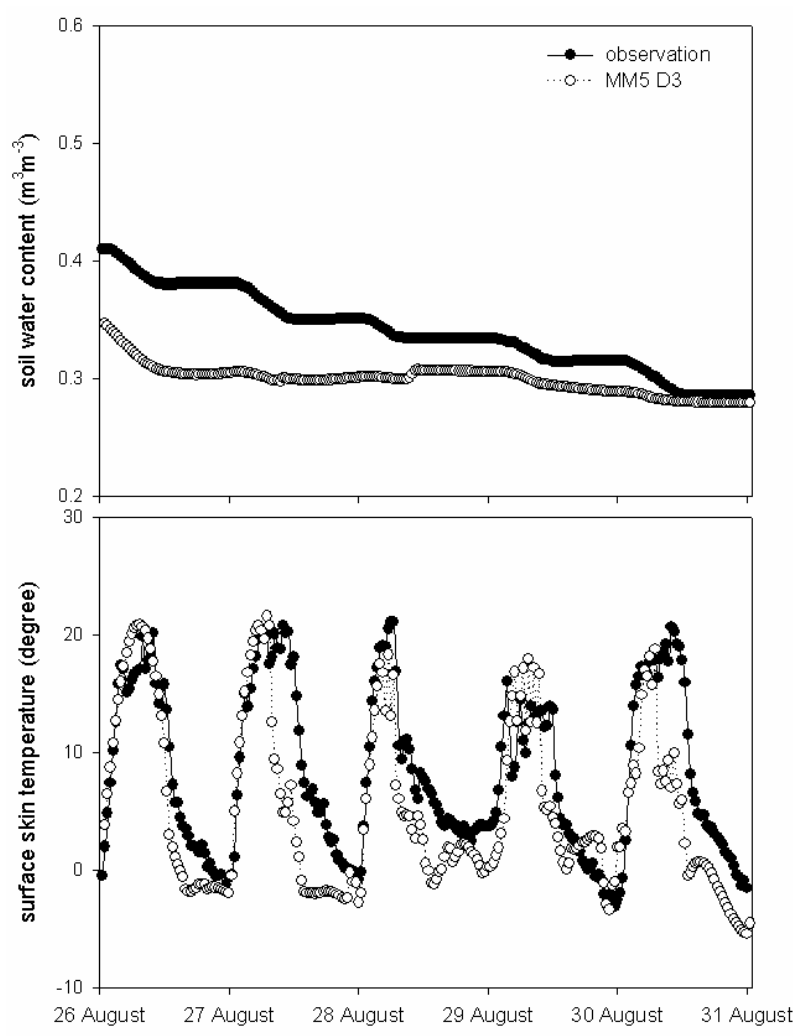

Fig. 11. Comparison of the simulated (domain 3) and observed surface temperature and soil water content.

\section{References}

Avissar, R. and Pielke, R. A.: A Parameterization of Heterogeneous Land Surfaces for Atmospheric Numerical Models and Its Impact on Regional Meteorology, Mon. Weather Rev., 117, 2113 2136, 1989.

Baldocchi, D., Falge, E., Gu, L. H., Olson, R., Hollinger, D., Running, S., Anthoni, P., Bernhofer, C., Davis, K., Evans, R., Fuentes, J., Goldstein, A., Katul, G., Law, B., Lee, X., Malhi, Y., Meyers, T., Munger, W., Oechel, W., Paw U, K. T., Pilegaard, K., Schmid, H. P., Valentini, R., Verma, S., Vesala, T., Wilson, K., and Wofsy, S.: FLUXNET: A new tool to study the temporal and spatial variability of ecosystem-scale carbon dioxide, water vapor, and energy flux densities, Bull. Am. Meteorol. Soc., 82, 2415-2434, 2001.

Baldocchi, D.D., Krebs, T. and Leclerc, M. Y.: "Wet/dry Daisyworld": a conceptual tool for quantifying the spatial scaling of heterogeneous landscapes and its impact on the subgrid variability of energy fluxes, Tellus, 57B(3), 175-188, 2005.

Bertoldi, G., Kustas, W. P., and Albertson, J. D.: Estimating spatial variability in atmospheric properties over remotely sensed land surface conditions, J. Appl. Meteorol. Clim., 47, 2147-2165, 2008.

Betts, A., Chen, F., Mitchell, K., and Janjic, Z.: Assessment of land surface and boundary layer models in two operational versions of the Eta model using FIFE data, Mon. Weather Rev., 125, 2896- 
2915, 1997.

Bonan, G. B., Levis, S., Kergoat, L., and Oleson, K. W.: Landscapes as patches of plant functional types: An integrating concept for climate and ecosystem models, Global Bio. Cy., 16, 1021, doi:10.1029/2000GB001360, 2002.

Brotzge, J. A.: A Two-Year comparison of the surface water and energy budgets between two OASIS sites and NCEP-NCAR reanalysis data, J. Hydrometeo., 5, 311-326, 2004.

Chen, F. and Dudhia, J.: Coupling an advanced land surfacehydrology model with the Penn State-NCAR MM5 modeling system. Part I: Model implementation and sensitivity, Mon. Weather Rev., 129, 569-585, 2001a.

Chen, F. and Dudhia, J.: Coupling an advanced land surfacehydrology model with the Penn State-NCAR MM5 modeling system, Part II: Preliminary model validation, Mon. Weather Rev., 129, 587-604, 2001b.

Choi, T., Hong, J., Kim, J., Lee, H., Asanuma, J., Ishikawa, H., Tsukamoto, O., Gao, Z., Ma, Y., Ueno, K., Wang, J., Koike, T., and Yasunari, T.: Turbulent exchange of heat, water vapor, and momentum over a Tibetan prairie by eddy covariance and flux variance measurements, J. Geoph. Res., 109, D21106, doi:10.1029/2004JD004767, 2004.

Dolman, A. J., Noilhan, J., Durand, P., Sarrat, C., Brut, A., Piguet, B., Butet, A., Jarosz, N., Brunet, Y., Loustau, D., Lamaud, E., Tolk, L., Ronda, R., Miglietta, F., Gioli, B., Magliulo, V., Esposito, M., Gerbig, C., Körner, S., Glademard, P., Ramonet, M., Ciais, P., Neininger, B., Hutjes, R. W. A., Elbers, J. A., Macatangay, R., Schrems, O., Pérez-Landa, G., Sanz, M. J., Scholz, Y., Facon, G., Ceschia, E., and Beziat, P.: The CarboEurope regional experiment strategy, Bull. Am. Meteorol. Soc., 87, 1367-1379, 2006.

Gutman, G. and Ignatov, A.: The derivation of the green vegetation fraction from NOAA/AVHRR for use in numerical weather prediction models, Int. J. Remote Sens., 19, 1533-1543, 1998.

Henderson-Sellers, A., Dickinson, R. E., Turbidge, T. B., Kennedy, P. J., McGuffiel, K., and Pitman, A. J. : Tropical deforestation: Modeling local to regional scale climate change, J. Geophys. Res., 98, 7289-7315, 1993.

Hong, S.-Y. and Pan, H.: Nonlocal boundary layer vertical diffusion in a medium-range forecast model, Mon. Weather Rev., 124, 2322-2339, 1996.

Hong, J., Choi, T., Ishikawa, H., and Kim, J.: Turbulence structures in the near-neutral surface layer on the Tibetan Plateau, Geophy. Res. Lett., 31, L15106, doi:10.1029/2004GL019935, 2004.

Hong, J. and Kim, J.: Simulation of surface radiation balance on the Tibetan Plateau, Geophy. Res. Lett., 35, L08814, doi:10.1029/2008GL033613, 2008.

Kaimal, J. and Finnigan, J.: Atmospheric Boundary Layer Flows: Their structure and measurement, Oxford University Press, New York, 1994.

Kain, J. and Fritsch, M.: Convective parameterization for mesoscale models: The Kain-Fritsch scheme, The Representation of $\mathrm{Cu}$ mulus Convection in Numerical Models, Meteor. Monogr., Am. Meteorol. Soc., 24. 165-170, 1993.

Kerschgens, G. and Heinemann, M.: Comparison of methods for area-averaging surface energy fluxes over heterogeneous land surfaces using high-resolution non-hydrostatic simulations, Int. J. Clim., 25, 379-403, 2005.
Kim, J., Guo, Q., Baldocchi, D. D., Leclerc, M. Y., and Schmid, H. P.: Upscaling fluxes from tower to landscape: Overlaying flux footprints on high resolution (IKONOS) images of vegetation cover, Agric. For. Meteorol., 136, 132-146, 2006.

Koren, V., Schaake, J., Mitchell, K. Duan, Q., Chen, F., and Baker, $\mathrm{J} .:$ A parameterization of snowpack and frozen ground intended for NCEP weather and climate models, J. Geophys. Res., 104, 19569-19585, 1999.

Lee, X., Massman, W., and Law, B. E.: Handbook of Micrometeorology. A Guide for Surface Flux Measurement and Analysis, Kluwer Academic Press, Netherland, 2004.

Li, F., Kustas, W. P., Anderson, M. C., Prueger, J. H., and Scott, R. L.: Effect of remote sensing spatial resolution on interpreting tower-based flux observations, Remote Sen. Environ., 112, 337 349, 2008.

McNaughton, K. G. and Brunet, Y.: Townsend's hypothesis, coherent structures and Monin-Obukhov similarity, Bound.-Lay. Meteorol., 102, 161-175, 2002.

Middelburg, J. J., Liss, P. S., Dentener, F. J., Kaminski, T., Kroeze, C., Malingreau, J.-P., Novák, M., Panikov, N. S., Plant, R., Starink, M., and Wanninkhof, R.: Working group report: Relations between scale, model approach and model parameters, in: Approaches to Scaling of Trace Gas Fluxes in Ecosystems, edited by: Bouwman, A. F., Elsevier Science, Amsterdam, Netherlands, 1999.

Mlawer, E. J., Taubman, S. J., Brown, P. D., Iacono, M. I., and Clough, S. A.: Radiative transfer for inhomogeneous atmosphere: RRTM, a validated correlated-k model for the longwave, J. Geophy. Res., 102, 16663-16682, 1997.

Oncley, S. P. and Dudhia, J.: Evaluation of surface fluxes from MM5 using observation, Mon. Weather Rev., 123, 3344-3357, 1995.

Pyles, R. D., Weare, B. C., Paw U, K. T., and Gustafson, W. Coupling between the University of California, Davis, advanced canopy-atmosphere - soil algorithm (ACASA) and MM5: Preliminary results for July 1998 for western north America, J. Appl. Meteorol., 42, 557-569, 2003.

Reisner, J., Rasmussen, R. M., and Bruintjes, R. T.: Explicit forecasting of supercooled liquid water in winter storms using the MM5 mesoscale model, Quart. J. Roy. Meteorol. Soc., 124, 1071-1107, 1998

Reiter, E. R., Sheaffer, J. D., Bossert, J. E., Smith, E. A., Stone, G., McBeth, R., and Zheng, Q.: Tibet Revisited-TIPMEX-86, Bull. Am. Meteorol. Soc., 68, 607-615, 1987.

Schmid, H. P.: Experimental design for flux measurements: Matching scales of observations and fluxes, Agric. For. Meteorol. 87, 179-200, 1997.

Sellers, P. J., Heiser, M. D., Hall, F. G.: Relations between surface conductance and spectral vegetation indices at intermediate $\left(100 \mathrm{~m}^{2}\right.$ to $\left.15 \mathrm{~km}^{2}\right)$ length scales, J. Geophy. Res., 17, 19033 19059, 1992.

Sellers, P. J., Heiser, M. D., Hall, F. G., Goetz, S. J., Strebel, D. E., Verma, S. B., Desjardins, R. L., Schuepp, P. M., and MacPherson, J. I.: Effects of spatial variability in topography, vegetation cover and soil moisture on area-averaged surface fluxes: A case study using the FIFE 1989 data, J. Geophy. Res., 100, $25607-$ $25629,1995$.

Sellers, P. J., Heiser, M. D., Hall, F. G., Verma, S. B. Desjardins, R. L., Schuepp, P. M., and MacPherson, J. I.: The impact of using 
area-averaged land surface properties - topography, vegetation condition, soil wetness - in calculations of intermediate scale (approximately $10 \mathrm{~km}^{2}$ ) surface-atmosphere heat and moisture fluxes, J. Hydrol., 190, 269-301, 1997. van der Molen, M. K. and Dolman, A. J.: Regional carbon fluxes and the effect of topography on the variability of atmospheric $\mathrm{CO}_{2}$. J. Geophy. Res., 112(D1), D01104, doi:10.1029/2006JD007649, 2007.

Willmott, C. J.: Some comments on the evaluation of model performance, Bull. Amer. Meteorol. Soc., 63, 1309-1313, 1982. 